\title{
A Mass Screening System for Short Stature in Children
}

\author{
Kanji Nagashima, Hideki Yagi, Shigenori Yutani, Hiroshi Miyake, Kazumichi Onigata and Akihiro Morikawa \\ Department of Pediatrics, Gunma University School of Medicine, Gunma, Japan
}

\begin{abstract}
We developed a mass screening system for short stature in elementary school children. The subjects of this mass screening were 153,679 pupils. This screening was done in two steps. In the primary screening, children with possible short stature were screened according to height criteria by grade designed to perform simple and efficient selection. In the second step, children with height below a - 2SD score were screened according to height criteria by chronological age. The case report forms, with body measurements, growth curve and height velocity curve for positive cases in the second screening, were returned to the mass-screening center where the need for further evaluation was determined. Of all the subjects, 2,331 were classified as positive. The necessity for further evaluation was recommended in 273 . Ninety-six of the 273 were actually seen at hospitals, and underlying diseases were revealed in 19 of them (GH deficiency, 10; hypothyroidism, 2; Turner syndrome, 6; and renal tubular acidosis, 1). The results indicate that short-stature children can be identified more efficiently without any particular additional examination, if body measurements obtained by annual checkups in school are combined with growth and annual height velocity curves.
\end{abstract}

Key words: short stature, mass screening

\section{Introduction}

A small number of children of short stature have endocrine disorders or chronic diseases [1]. Treatment of the underlying diseases may therefore lead to the recovery of health and subsequent normal growth. Although many children of short stature have psychosocial discomfort, they usually look healthy. Furthermore, those who are regularly with the children tend to overlook the abnormally short stature. It is therefore useful to develop a mass screen-

Received: July 12, 1995

Accepted: July 22, 1996

Correspondence: Dr. Kanji Nagashima, Department of Pediatrics, Gunma University School of Medicine, 3-3915 Showa-machi, Maebashi, Gunma 371, Japan ing system for detecting children of abnormally short stature [2]. This article presents the results of our mass screening for short stature conducted in elementary school children and proposes a guide for a sound community approach to height disturbances.

\section{Materials and Methods}

The subjects of this mass screening were first to sixth grade school children in Gunma Prefecture. Body measurements obtained by conventional regular annual checkups in school were used for this screening. Height was measured in the usual manner with a stadiometer with a direct read-off counter. In brief, the individual's heels and buttocks were against the wall in the upright position; the eyes were looking 
straight ahead, with the head in the Frankfort plane; mild upward pressure was exerted on the mastoid region; and a right angle device was lowered against the top of the head. A subject was classified into the short stature group if his or her height was scored less than - 2SD. The SD score was calculated by using the 1988 statistical data from the Office of the Ministry of Education [3].

Prior to the mass screening, the table of height criteria (Table 1) and the case report form (Fig. 1) for recording body measurements, growth curve and height velocity curve [4], were delivered to each school. School nurses or teachers were involved in the screening, which was performed in two steps.

In the primary screening, children of possible short stature were screened according to Table 1-A: Height criteria by Grade. This screening was designed to perform simple and efficient selection. The height criteria standard was set at a $-2 \mathrm{SD}$ score for the youngest children, those born in March (in Japan, children born from April to March of the next year are included in the same grade).

After determining their chronological ages at the time of measurement, children classified as primary screening-positive were evaluated for short stature according to Table 1-B: Height criteria by Chronological Age [4]. This table shows the - 2SD scores. If the height of a child was lower than that value, the child was classified as secondary screening-positive. The body measurements, growth curves, and height velocity curves [4] of positive cases were then entered in the case report form (Fig. 1), which was returned to the screening center.

At the center, the SD score for each child was calculated from the data received. Two pediatric endocrinologists evaluated the pattern of the growth and height velocity curves and identified to the children in need of further evaluation. Table 2 shows the categories of evaluation. If both physicians reached the same conclusion, it

\section{Table 1}

A. Height criteria by Grade in primary screening

\begin{tabular}{ccc}
\hline Grade & $\begin{array}{c}\text { Boy } \\
\text { (cm) }\end{array}$ & $\begin{array}{c}\text { Girl } \\
\text { (cm) }\end{array}$ \\
\hline 1st & 110 & 109 \\
2nd & 115 & 114 \\
3rd & 120 & 119 \\
4th & 124 & 124 \\
5th & 129 & 129 \\
6th & 133 & 136 \\
\hline
\end{tabular}

B. A part of height criteria by chronological age in secondary screening

\begin{tabular}{|c|c|c|c|}
\hline (year) & $\begin{array}{l}\text { ge } \\
\text { (month) }\end{array}$ & $\begin{array}{l}\text { Boy } \\
\text { (cm) }\end{array}$ & $\begin{array}{l}\text { Girl } \\
\text { (cm) }\end{array}$ \\
\hline 6 & 0 & 104.6 & 104.7 \\
\hline 6 & 1 & 105.0 & 105.1 \\
\hline 6 & 2 & 105.4 & 105.4 \\
\hline 6 & 3 & 105.7 & 105.7 \\
\hline 6 & 4 & 106.2 & 105.9 \\
\hline 6 & 5 & 106.7 & 106.2 \\
\hline 6 & 6 & 107.1 & 106.4 \\
\hline 6 & 7 & 107.5 & 106.8 \\
\hline 6 & 8 & 108.0 & 107.2 \\
\hline . & . & . & . \\
\hline . & . & . & . \\
\hline . & . & . & . \\
\hline . & . & . & . \\
\hline
\end{tabular}

was included. If the results were not in agreement, the evaluation of short stature was discussed with other pediatric endocrinologists and decided by the majority. The results of the evaluations were sent back to the health personnel in each school and used as a part of the data for health consultation in each school. The ultimate decision for further evaluation at the hospital was made by the parents. The purpose of this screening system was to identify children of short stature with undrelying diseases. Alternatively, to avoid false negatives, we avoided the term "normal" in children for whom further evaluations were not suggested. For these children, 

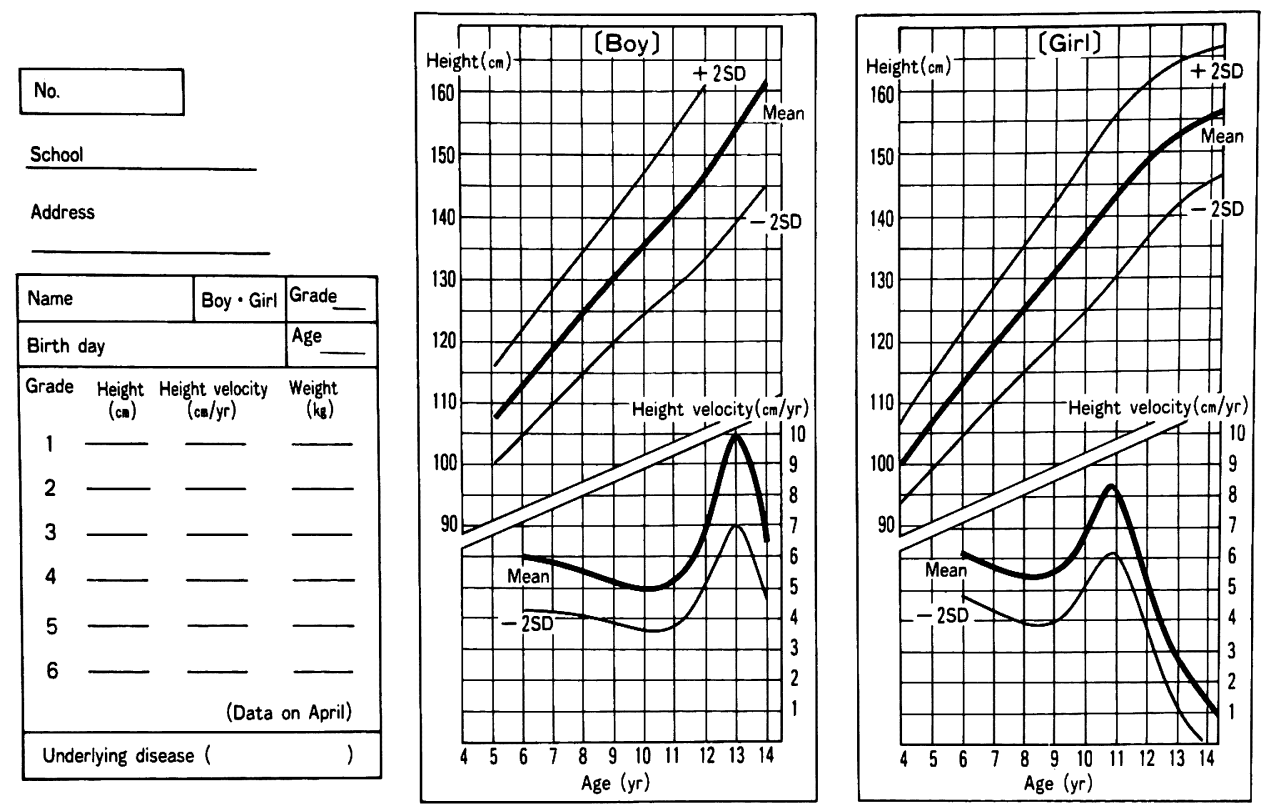

Fig. 1 Case report form for recording body measurement, growth curve, and height-velocity curve used for referrals in secondary screening.

Table 2 Category of short stature

\begin{tabular}{|c|c|c|c|c|c|}
\hline \multirow[t]{2}{*}{ Category } & \multicolumn{4}{|c|}{ Bases of decision } & \multirow[t]{2}{*}{ Recommendations } \\
\hline & \multicolumn{3}{|c|}{ Heigh SD Score } & \multirow{2}{*}{$\begin{array}{l}\text { Height velocity } \\
\text { Only one record }\end{array}$} & \\
\hline $\mathrm{A}-0$ & -2.00 & $\sim$ & -2.49 & & Follow-up observation \\
\hline A-1 & -2.00 & $\sim$ & -2.49 & $>-1.5 \mathrm{SD}$ & Follow-up observation \\
\hline A-2 & -2.00 & $\sim$ & -2.49 & $\leqq-1.5 \mathrm{SD}$ & Further evaluation \\
\hline B-0 & -2.50 & $\sim$ & -2.99 & Only one record & Follow-up observation \\
\hline B-1 & -2.50 & $\sim$ & -2.99 & $>-1.5 \mathrm{SD}$ & Follow-up observation \\
\hline B-2 & -2.50 & $\sim$ & -2.99 & $\leqq-1.5 \mathrm{SD}$ & Further evaluation \\
\hline $\mathrm{C}-0$ & -3.00 & $\sim$ & -3.49 & Only one record & Follow-up observation \\
\hline C-1 & -3.00 & $\sim$ & -3.49 & $>-1.5 \mathrm{SD}$ & Follow-up observation \\
\hline $\mathrm{C}-2$ & -3.00 & $\sim$ & -3.49 & $\leqq-1.5 \mathrm{SD}$ & Further evaluation \\
\hline $\mathrm{D}$ & \multicolumn{4}{|c|}{ Below -3.50} & Further evaluation \\
\hline E & \multirow{2}{*}{\multicolumn{4}{|c|}{$\begin{array}{l}\text { Cases with final diagnosis } \\
\text { Incomplete records }\end{array}$}} & \\
\hline $\mathrm{F}$ & & & & & \\
\hline
\end{tabular}


Table 3 Result of mass-screening for short stature

\begin{tabular}{|c|c|c|c|c|c|c|c|c|c|c|c|c|c|c|c|}
\hline \multirow[b]{2}{*}{ Grade } & \multirow[b]{2}{*}{ Sex } & \multirow[b]{2}{*}{ Subjects } & \multirow[b]{2}{*}{ Referrals } & \multicolumn{12}{|c|}{ Category } \\
\hline & & & & $\begin{array}{l}\text { A-0 } \\
\text { (n) }\end{array}$ & $\begin{array}{l}\text { A-1 } \\
\text { (n) }\end{array}$ & $\begin{array}{l}\text { A-2 } \\
\text { (n) }\end{array}$ & $\begin{array}{l}\text { B-0 } \\
\text { (n) }\end{array}$ & $\begin{array}{l}\text { B-1 } \\
\text { (n) }\end{array}$ & $\begin{array}{l}\text { B-2 } \\
\text { (n) }\end{array}$ & $\begin{array}{l}\text { C-0 } \\
\text { (n) }\end{array}$ & $\begin{array}{l}\text { C-1 } \\
\text { (n) }\end{array}$ & $\begin{array}{l}\text { C-2 } \\
\text { (n) }\end{array}$ & $\begin{array}{c}\text { D } \\
\text { (n) }\end{array}$ & $\begin{array}{c}E \\
(n)\end{array}$ & $\begin{array}{c}F \\
(n)\end{array}$ \\
\hline \multirow[t]{2}{*}{1 st } & $\mathrm{F}$ & 11,843 & 232 & 148 & 0 & 0 & 52 & 0 & 0 & 10 & 0 & 0 & 2 & 16 & 4 \\
\hline & M & 12,409 & 189 & 126 & 0 & 0 & 39 & 0 & 0 & 10 & 0 & 0 & 2 & 11 & 1 \\
\hline \multirow[t]{2}{*}{ 2nd } & $\mathrm{F}$ & 11,857 & 182 & 4 & 111 & 2 & 0 & 33 & 0 & 4 & 0 & 7 & 2 & 16 & 3 \\
\hline & M & 12,779 & 182 & 5 & 121 & 1 & 0 & 28 & 5 & 0 & 1 & 4 & 5 & 12 & 0 \\
\hline \multirow[t]{2}{*}{$3 \mathrm{rd}$} & $\mathrm{F}$ & 12,749 & 183 & 3 & 120 & 2 & 0 & 24 & 5 & 0 & 1 & 6 & 5 & 12 & 5 \\
\hline & $\mathrm{M}$ & 12,550 & 167 & 4 & 104 & 6 & 0 & 22 & 6 & 0 & 3 & 3 & 2 & 9 & 8 \\
\hline \multirow[t]{2}{*}{ 4th } & $\mathrm{F}$ & 12,204 & 199 & 4 & 115 & 7 & 1 & 21 & 19 & 0 & 2 & 7 & 2 & 15 & 6 \\
\hline & M & 13,063 & 207 & 2 & 135 & 7 & 0 & 27 & 7 & 0 & 2 & 7 & 3 & 14 & 3 \\
\hline \multirow[t]{2}{*}{5 th } & $\mathrm{F}$ & 13,092 & 190 & 1 & 123 & 11 & 2 & 26 & 13 & 1 & 0 & 6 & 0 & 6 & 1 \\
\hline & M & 13,549 & 192 & 0 & 127 & 6 & 0 & 24 & 10 & 0 & 1 & 7 & 0 & 12 & 5 \\
\hline \multirow[t]{2}{*}{6 th } & $\mathrm{F}$ & 13,330 & 231 & 3 & 130 & 9 & 1 & 40 & 22 & 0 & 2 & 8 & 2 & 12 & 2 \\
\hline & $\mathrm{M}$ & 14,254 & 177 & 3 & 118 & 11 & 0 & 13 & 13 & 0 & 0 & 6 & 0 & 9 & 4 \\
\hline \multirow{2}{*}{$\begin{array}{c}\text { Total (n) } \\
(\%)\end{array}$} & & 153,679 & 2,331 & 303 & 1,204 & 62 & 95 & 258 & 100 & 25 & 12 & 61 & 25 & 144 & 42 \\
\hline & & & 1.52 & 0.20 & 0.78 & 0.04 & 0.06 & 0.17 & 0.07 & 0.02 & 0.01 & 0.04 & 0.02 & 0.09 & 0.03 \\
\hline
\end{tabular}

we have recommended follow-up observation.

\section{Results}

The elementary school children in Gunma Prefecture subjected to this mass screening totalled 153,679 children ( 78,604 boys and 75,075 girls). Of this total, 2,331 ( 1,114 boys and 1,217 girls) were classified as secondary screeningpositive cases. They accounted for 1.52 percent of all subjects. Table 3 shows the results of the evaluations by the pediatric endocrinologists. Complete evaluation was recommended in 273 children. They accounted for 0.19 percent of all subjects and 11.7 percent of all secondary screening-positive cases. Five months after the results were delivered to the schools, 96 children for whom evaluation was considered necessary have been seen at the hospital. Table 4 shows the
Table 4 Final diagnosis after further evaluation

\begin{tabular}{lcc}
\hline Diagnosis & Number of cases & Percent \\
\hline GH deficiency & 10 & 10.4 \\
Turner syndrome & 6 & 6.3 \\
Hypothyroidism & 2 & 2.1 \\
Renal tubular acidosis & 1 & 1.0 \\
Delayed adolescence & 14 & 14.6 \\
Constitutional short stature & 63 & 65.6 \\
Total & 96 & 100.0 \\
\hline
\end{tabular}

results of diagnosis in these children. In nineteen cases, causes of short stature were identified. Sixty-three children presented no pathological cause for their short stature. Fourteen children were considered to have delayed adolescence due to lack of sexual development, slightly delayed bone maturation, no abnormal 
laboratory findings and a family history of delayed adolescence.

\section{Discussion}

Some researchers reported on screening programs for short stature that height records used were determined by one-point measurement-a method that resulted in excessive false-positive referrals $[5,6]$. Some reports recommended that measurement of urinary growth hormone or insulin-like growth factor- 1 binding protein 3 is a useful screening parameter for GH deficiency [7, 9] but GH deficiency is only one of the causes of short stature in children.

In our screening system, no biochemical analysis was performed to detect short stature. Briefly, we used only body measurements obtained at annual check-ups in school and a growth curve and height-velocity curve were used to decrease the number of false-positive referrals. This system can be widely used, because no special cost is involved.

By using SD scores with growth and heightvelocity curves we can also detect a greater number of abnormal cases more efficiently. The proportion of subjects in need for further evaluation was therefore reduced to 0.19 percent of all subjects. Our screening system has a risk of false positive, because subjective evaluation is used but this may not be a significant problem because the main purpose of this screening system is to detect short children with abnormal growth. As an unexpected result of this screening, school health care providers have begun to turn their attention to short stature in children. The incidence of cases with possible late puberty was high among the ones in need of further evaluation. Taking these characteristics into consideration, it is difficult to accurately detect this condition by using the case report forms from the present screening. We recommend that in future the "presence or appearance of secondary sexual characteristics" should be included in the case report form for older children.

Only thirty-five percent of children for whom further evaluation was considered necessary were actually seen at medical institutions. This was expected because children were not forced to do so within a certain period of time and school health personnel were not forced to immediately notify children or parents about the results of the evaluation. The decision to see a doctor was left to their parents in the present mass screening. Evaluation of the effect of GH therapy on non-endocrine short stature is in progress [913 ], but this treatment has not yet proven effective.

Our data indicate that it seems possible to conduct mass screening for short stature with only body measurements obtained by annual check-ups in school. If serial measurements obtained at each school are assessed at regular intervals, we are able to establish a more efficient mass screening system for short stature.

\section{References}

1. Smith DW. Approach to the diagnosis, classification, and nature of growth deficiency disorders. In: Growth and its disorders. Philadelphia: WB Saunders, 1977: 62-9.

2. Cross AW. Health screening in school. Part II. J Pediatr 1985; 107: 653-61.

3. Agency report. Statistics for the growth of school boys and girls (6-18 years) referred from the Ministry Report on Statistics for Schools, 1988: Ministry of Education of Japan.

4. Suwa S, Tachibana K, Maesaka H, Tanaka T, Yokoya S. Longitudinal standards for height and height velocity for Japanese children from birth and maturity. Clin Pediatr Endocrinol 1992; 1: 513.

5. Green AA, Macfarlane JA. Method for the earlier recognition of abnormal stature. Arch Dis Child 1983; 58: 535-7.

6. Lacey KA, Parkin JM. Causes of short stature: a community study of children in Newcastle-uponTyne. Lancet 1974; 1: 42-5. 
7. Walker JM, Wood PJ, Williamson S, Betts P. Urinary growth hormone excretion as a screening test for growth hormone deficiency. Arch Dis Child 1990; 65: 89-92.

8. Blum WF, Ranke MB, Kietzmann K, Gauggel E, Zeisel HJ, Bierich JR. A specific radioimmunoassay for the growth hormone (GH) dependent somatomedin-binding protein: its use for diagnosis of GH deficiency. J Clin Endocrinol Metab 1990; 70: 1292-8.

9. Kida K, Ito T, Hayashi M, Kaino Y, Goto Y, Ikeuchi M, et al. Urinary excretion of human growth hormone in children with short stature: correlation with pituitary secretion of human growth hormone. J Pediatr 1992; 120: 233-7.

10. Rudman D, Kutner MH, Blackston RD, Cushman RA, Bain RP, Patterson JH. Children with normal-variant short stature: treatment with human growth hormone for six months. N Engl J Med 1981; 305: 123-31.

11. Gertner JM, Genel M, Gianfredi SP, Hinz RL, Rosenfeld RG, Tamborlane WV. Prospective clinical trial of human growth hormone in short children without growth hormone deficiency. J Pediatr 1984; 104: 172-6.

12. Vilet GV. Use of growth hormone in the management of growth disorders. In: Sizonenko PC, Aubert ML, editors, Developmental endocrinology. Serono Symp. New York: Raven Press, 1990: 195-202.

13. Chanoine JP, Vanderschueren-Lodeweyckx M, Maes M, Thiry-counson G, Craen M, Vliet GV. Growth hormone (GH) treatment in short normal children: absence of influence of time of injection and resistance to $\mathrm{GH}$ autofeedback. J Clin Endocrinol Metab 1991; 73: 1269-75. 